\title{
Pascual de Gayangos y la historia medieval de España
}

\author{
Cristina Álvarez Millán \\ UNED $^{1}$
}

\section{RESUMEN}

Este trabajo ofrece una carta inédita de

Pascual de Gayangos a Serafín

Estébanez Calderón, en la que además

de relatarle detalles de su vida en

Londres, proporciona a su amigo una amplia información histórica sobre la posible localización geográfica del castillo de Bobastro y la rebelión de lbn Hafsūn. A propósito de esta carta, se destacan aspectos poco conocidos hasta ahora de su labor en el campo de la historia medieval española.

\section{PALABRAS CLAVE}

Pascual de Gayangos, S. Estébanez Calderón, Bobastro, Ibn Hafsūn, Patrimonio documental español, historia de la archivistica española.

\section{ABSTRACT}

This work presents an unpublished letter from Pascual de Gayangos to Serafin Estébanez Calderón, in which he describes details of his life in London and provides his friend with a wealth of data regarding Ibn Hafșun's rebellion as well as the possible geographical location of the castle of Bobastro. The introductory essay highlights some hitherto unknown aspects of Gayangos's contributions to medieval Spanish history.

\section{KEYWORDS}

Pascual de Gayangos, S. Estébanez Calderón, Bobastro, Ibn Hafsūn, Spanish archival patrimony, history of Spanish archivism.

' El presente trabajo, realizado gracias a un Contrato de Investigación del Programa Ramón y Cajal del Ministerio de Ciencia y Tecnología, no hubiera sido posible sin la ayuda y constante atención recibida del personal de la Biblioteca de la Real Academia de la Historia (Asunción Miralles de Imperial, M. $^{a}$ Dolores Gella, Julio Garcia, Antonio Congosto y Ricardo Leoz) durante el disfrute de una Beca Postdoctoral de la Comunidad de Madrid. 
Pascual de Gayangos y Arce (1809-1897) es una figura conocida, aunque también mayoritariamente borrosa todavia para muchos. Arabista, hispanista, bibliófilo, bibliógrafo y académico entre otras muchas cosas, sus cartas no dejan indiferente a nadie por su amenidad y humanidad, así como por su condición de fuente para su propia biografía y para numerosas disciplinas ${ }^{2}$. Aunque en los últimos años se ha empezado a recuperar la memoria de este erudito y a destacar su papel en ámbitos como la literatura hispánica, la numismática o el actual patrimonio bibliográfico español ${ }^{3}$, aún estamos lejos de hacer justicia a la transcendencia del personaje. Por ello, como homenaje a José Luis Martín, el propósito de este trabajo no es otro que reivindicar su faceta de historiador y, más concretamente, la de medievalista. Por razones de extensión, me limitaré a resumir su labor en este campo a partir de su producción bibliográfica, de sus papeles personales y de la documentación de archivo que he manejado, para dejar hablar después a una de sus cartas ${ }^{4}$. Datada en julio de 1841 y enviada desde Londres a Serafín Estébanez Calderón ${ }^{5}$, la primera parte complementa dos epístolas publicadas en un trabajo anterior, dirigidas en mayo del mismo año a Martín Fernández de Navarrete y Vicente González Arnao, Director y Secretario de la Real Academia de la Historia respectivamente ${ }^{6}$. Si esta primera parte confirma los avatares anímicos y profesionales de Gayangos en Londres descritos en las anteriores misivas, la segunda - dedicada fundamentalmente a la localización geográfica del castillo de Bobastro y a la rebelión de Ibn Hafșūn- no sólo da fe de su capacidad epistolar y de su incansable actividad buscando, estudiando y copiando materiales de interés para la historia de España en bibliotecas y archivos (nacionales y extranjeros), sino que también ilustra su faceta de historiador y su generosidad cientifica.

Una biografía bastante completa y actualizada, junto a una relación de materiales publicados e inéditos del epistolario de Gayangos, puede verse en SANCHEz MariAnA, M.: "Presupuestos para una edición del epistolario de Don Pascual de Gayangos", Pliegos de Bibliofilia, 3, tercer trimestre (1998), pp. 57-65. Véase también, VALLVE. J.: "Pascual de Gayangos (1809-1897): A propósito del centenario de su muerte", BRAH, CXCIV.3 (1997), pp. 461-488.

3 Vilar ramirez, J. B.: «El Arabista Pascual de Gayangos en los origenes de la ciencia numismática española. Su viaje a París y Londres en 1835", Sharq al-Andalus, 1 (1984), pp. 161-165; López Estrada, Francisco: "Pascual de Gayangos y la literatura medieval castellana", Alfinge. 4 (1986), pp. 11-29; VILAR, $M$.: «Pascual de Gayangos, traductor e intérprete de ingles y otras lenguas extranjeras en el Ministerio de Estado (1833-1837)", Boletín de la Biblioteca Menéndez Pelayo. 73 (1997), pp. 43-47 (reprod. en: VILAR, M.: Docentes, traductores e interrpretes de la lengua inglesa en la España del siglo xix. Juan Calderón. los hermanos Usoz y Pascual de Gayangos, Murcia, Universidad de Murcia, 2004); VILAR Ramirez, J. B.: «EI viaje de Pascual de Gayangos a Marruecos en 1848 en busca de manuscritos y libros árabes", Boletín de la Biblioteca Menendez Pelayo, 73 (1997), pp. 29.41

${ }^{4}$ Madrid, RAH, 9/4444. Debo expresar mi agradecimiento a Asunción Miralles de Imperial por comunicarme el hallazgo de este material al revisar el legajo en busca de otra documentación. La carpetilla contiene tres cartas más de Gayangos que, escritas unos años más tarde y relacionadas con otro periodo de su vida, serán publicadas próximamente

"Manzanares de Cirre, M.: «El arabismo romántico de Estébanez Calderón, El Solitario». Publications of the Modern Language Association of America, 77.4, part l (1962), pp. 414.418; CANOVAS DEL. CASThlo, A.: "El Solitario" y su tiempo. Biografia de D. Serafín Estébanez Calderón y critica de sus obras. 2 vols. Madrid: Imp. Antonio Perez Dubrull. 1883. Los apéndices C y D del tomo segundo, pp. 317-405, reproducen la correspondencia entre Estébanez y Gayangos; la carta aqui editada es contestación a la de S. Estébanez Calderón de 16 de junio de 1841, pp. 371-376.

i Álvarez Millán, C.: "A propósito de dos cartas enviadas a la Real Academia de la Historia: Pascual 
La carta que incluimos aquí es sin duda una muestra representativa de esos aspectos vitales de la personalidad de Gayangos, aplicables a todos los campos del saber que cultivó. No fue casualidad que, como acertadamente apunta Mar Vilar, Gayangos impulsara el desarrollo del hispanismo en el mundo anglosajón y se convirtiera en referencia obligada de cuantos se interesaron por los más variados aspectos de la cultura hispánica dentro y fuera de nuestro país ${ }^{7}$. De toda su actividad como medievalista, la más reconocida hasta ahora es aquella relacionada con la literatura hispánica medieval, estrechamente ligada a su condición de bibliófilo y bibliógrafo. Pascual de Gayangos virtió al castellano una obra extranjera fundamental sobre la historia de la literatura española, la de George Ticknor, cuya preparación dependió en gran medida de los libros que Gayangos prestó a - o adquirió para - el autor, y en cuya traducción añadió desinteresadamente materiales propios $^{8}$. A expensas de determinar algún día hasta qué punto fue también responsable directo de las ediciones del Cancionero de Baena o de obras más tardías de la literatura española como el Poema de Mohamed Rabadán ${ }^{9}$, sus publicaciones relacionadas con textos literarios medievales españoles y sus correspondientes introducciones históricas son bien conocidas de los especialistas actuales; entre ellas, El libro de las aves de la caça del canciller Pero López de Ayala (1869) e Historia de Enrique Fi de Oliva, rey de Iherusalem, Emperador de Constantinopla (1871) publicadas en la colección de la Sociedad de Bibliófilos Españoles, Libros de caballerias (1874) y Escritores en prosa anteriores al siglo XV (1884) publicadas en la Biblioteca de Autores Españoles, o Breve tractado de Grimalte y Gradissa de Juan de Flores (1883). Menos familiares resultan sus reseñas, que entonces denominadas "crónicas literarias", dentro de este campo se convierten en auténticos estudios monográficos en el caso de la edición alemana del Viaje por España del Barón Rosmithal de Blatna, de la traducción francesa del Conde Lucanor y de la edición árabe de Las Mil y una noches ${ }^{10}$.

de Gayangos y el Patrimonio Bibliogrático Español», Pliegos de Bibliofilia, 24.4 (2003), pp. 3-32

7 VILAR, M.: "Pascual de Gayangos, traductor e intérprete...", Docentes, traductores e intérpretes, p. 234. Sobre la influencia que Gayangos ejerció en los circulos iritelectuales europeos y norteamericano. véase HeIDE, C.: The Many Lives of Pascual de Gayangos. Ph. D. Dissertation. University of Edin. burgh, 2005

8 TickNon, M. G.: Historia de la Literatura Española; traducida al castellano, con adiciones y notas criticas por Pascual de Gayangos y Enrique de Vedia. 4 vols., Madrid: Imprenta de M. Rivadeneyra, 1851. 1856. Sobre la deuda de Ticknor con Gayangos, véase TickNOR, G.: Life, Letters and Journals of George Ticknor. 2 vols. Boston: James R. Osgood and Company, late Ticknor \& Fields, 1877, II, pp. 246-249 y TICKNOR, G.: Letters to Pascual de Gayangos; ed. by Clara Louisa Penney. New York: Hispanic Society of America, 1927

9 En cuanto a El Cancionero de Juan Alfonso de Baena (Madrid: M. Rivadeneyra, 1851), no son pocas las referencias que atribuyen su edición a Gayangos, aunque en la obra figuren como responsables sus amigos Eugenio de Ochoa y el Marqués de Pidal. En cuanto a la publicación del poema completo de Mohamed Rabadán - que Gayangos conocia bien y del que incluyó fragmentos en el cuarto volumen de Ticknor y en alguno de sus primeros trabajos - fue publicado por H. E. J. STANLEY en Journal of the Royal Asiatic Society (New Series). Ilt. 1 (1867), pp. 81-104; III.2 (1868), pp. 379-413; IV.1 (1870), pp. 138177; V (1871), pp. 119-140 y 303-337; VI.1 (1873), pp. 165-212. Aunque este excéntrico aristócrata había estudiado árabe en Cambridge y se habia convertido al Islam, el tipo de notas y el hecho de que todas estén redactadas en perfecto español hace patente la colaboración de Gayangos. Véase, HARVEY, L. P.: "British Arabists and al-Andalus", Al-Qantara, 13.2 (1992), pp. 423-436, esp. 429-431.

10 Respectivamente en Revista Española de Ambos Mundos, 1 (1853), pp. 739-755, Revista Espa- 
Mucho más prolífica y voluminosa es su bibliografía relacionada con la historia de España, que abarca desde la dominación islámica hasta el siglo XVII ${ }^{11}$. Al papel de Gayangos en el desarrollo de los estudios sobre la España musulmana nos referiremos después. En cuanto a su labor como historiador de la España cristiana y, particularmente de los siglos $\times \vee$ y $X V I$, la relación de su contribución historiográfica, sencillamente, desbordaría la extensión de este trabajo. Por ello, destacaremos aqui otras actividades suyas en este campo hasta ahora poco o nada conocidas dentro de nuestras fronteras, que constituyen empresas altruistas y que, en el segundo caso, siendo calificable de verdadera hazaña, tuvo bastante mayor alcance que cualquier obra impresa.

La primera de esas empresas fue magistralmente descrita hace cerca de cincuenta años por $\mathrm{C}$. Harvey Gardiner y se resume en el título de su artículo "Prescott's Most Indispensable Aid: Pascual de Gayangos» ${ }^{12}$. La relación entre nuestro erudito y el historiador americano tuvo su inicio a partir de la reseña que Gayangos realizó a instancias de G. Ticknor sobre la obra de W. H. Prescott, The History of the Reign of Ferdinand and Isabella, the Catholic Kings of Spain (3 vols. London, 1838) ${ }^{13}$. Desde entonces y a lo largo de veinte años, Gayangos se convirtió en eficaz y desinteresado colaborador de Prescott como autor de la historia de la conquista de Méjico, de la historia de la conquista de Perú y de la historia del reinado de Felipe $1{ }^{14}$. Ciego de un ojo y parcialmente del otro, apegado al confort de su familia y de su ciudad -Boston- y romántico hasta el punto de descartar la posibilidad de visitar los paises sobre cuya historia habia escrito, Prescott contó con una vasta red de proveedores bibliográficos y documentales en Méjico, Inglaterra, España, Francia, Italia, Alemania, Austria, Bélgica y Holanda. Sin embargo, quien contribuyó de forma crucial y de quien dependió la calidad de sus trabajos históricos fue Gayangos, que - parafraseando a Gardiner- reunía en sí mismo las dosis necesarias de entusiasmo, habilidad lingüística y paleográfica, capacidad de trabajo, perspicacia intelectual y un sexto sentido especial como investigador para localizar material bibliográfico y de archivo. Además de proporcionar a Prescott materiales de su colección privada para que enriqueciera las sucesivas ediciones de la historia de los Reyes Católicos, en 1840 Gayangos copió para él cerca de dos mil documentos del British Museum, realizó un índice de los materiales de esta institución que podian ser útiles para los proyectos de Prescott y comprobó el interés

ñola de Ambos Mundos, 2 (1854), pp. 385-402 y Antologia Española, 3 (1848), pp. 43-59.

11 Una relación exhaustiva - aunque seguramente, aún lejos de ser completa- de las publicaciones de P. de Gayangos puede verse en Álvarez Ramos, M. A. y Álvarez MiLlán, C.: Los viajes literarios de Pascual de Gayangos como Comisionado de la Real Academia de la Historia y el origen de la archivistica española moderna (1850-1857), en prensa.

12 Gardiner, C. H.: "Prescott's Most Indispensable Aide: Pascual de Gayangos», The Hispanic American Historical Review, 39.1 (1959), pp. 81- 115.

1.3 The Edinburgh Review LXVIII, January, (1839) 376-401.

${ }_{14}$ Prescott, W. H.: History of the Conquest of Mexico, with a Preliminary view of the Ancient Mexican Civilization, and the life of the Conqueror Hernando Cortes. 3 vols. New York: Harper \& Brothers, 1843; History of the Conquest of Peru, with a Preliminary View of the Civilization of the Incas. 2 vols. New York: Harper \& Brothers, 1847; History of the Reign of Philip the Second, King of Spain. 2 vols. Boston: 
potencial de la documentación del State Paper Office con el mismo fin. En 1841 Gayangos fue nombrado Vice-Cónsul de Túnez; aunque ni el cargo ni el viaje llegaron a materializarse, ante la perspectiva de una larga estancia en el Norte de África, la mayor parte de su biblioteca privada -incluyendo especialmente las piezas más valiosas - fue empaquetada y enviada a Boston para uso de Prescott hasta su regreso. El hecho de que la permanencia de Gayangos en Londres se alargara, le permitió acceder a archivos y bibliotecas privadas donde seguir buscando documentación para el historiador americano, además de la adquisición de materiales relevantes en subastas y la contratación de copistas para transcribir documentos cuya exactitud él comprobaba después. Cuando en la primavera de 1843 Gayangos ejecutaba por fín su ansiado regreso a España, lo hizo pasando previamente por Bruselas y Francia con el fin de inspeccionar sus bibliotecas, cuyos fondos resultaron decepcionantes para los fines de Prescott. Una vez en España, Gayangos no dejó de inspirar, asesorar y -sobre todo-documentar los proyectos del americano, visitando al efecto la Biblioteca Nacional, El Escorial y, en junio de 1844, el archivo de Simancas; este último, incluso a pesar de la nefasta situación y regulación archivistica española y de la abrumadora tristeza por la reciente muerte de uno de sus hijos. En palabras de Gardiner con respecto a la labor de Gayangos en este fondo documental, "sin su capacidad de selección, rapidez, voluntad de copista, diplomacia, perseverancia - la rara combinación de habilidades académicas de las cuales Gayangos estaba compuesto [...] probablemente Prescott no hubiera escrito sobre Carlos $V$ y no hubiera aportado nada significativo sobre Felipe $\|{ }^{15}{ }^{15}$. La colaboración de Gayangos en las obras de Prescott continuó hasta la muerte de éste en enero de 1859 y aunque ya no fue tan intensa, cabe destacar aquí otras dos citas de Gardiner que sintetizan - lo que acertadamente denomina - la labor de cooperación intelectual internacional de Gayangos: "Prescott nunca recibió tanto por tan poco en toda una vida [dedicada a] buscar y adquirir ingredientes para sus historias" y "Gayangos [...] hizo posible los importantes trabajos de aquel genio histórico americano. Y mientras Prescott se erija como el mejor intérprete decimonónico de la cultura española de habla inglesa, Gayangos merece ser recordado como su mejor y más indispensable ayuda" ${ }^{16}$.

La pasión de Gayangos por la historia nacional, su inteligente voluntad por preservar los restos materiales de nuestro pasado histórico, sus conocimientos paleográficos y su experiencia en archivos y bibliotecas de España, Inglaterra o Francia -entre otras- sin duda tuvo mucho que ver con otra gran empresa suya, ciertamente decisiva para la historiografia medieval española. Como adelanto al libro que sobre los viajes literarios de Gayangos como comisionado de la R.A.H. verá la luz próximamente $y$, desde luego, como argumento fundamental para reivindicar en este trabajo la faceta medievalista de Gayangus, es imprescindible mencionar aqui su labor de salvamento de gran parte de los fondos documentales de proce-

\footnotetext{
Phitlips, Sampson \& Co., 1855.

is Gardiner, C. H.: "Prescott's Most Indispensable Aide...", p. 104

16 Gardiner, C. H.: «Prescott's Most Indispensable Aide...", p. 105 y 115 respectivamente.
} 
dencia monástica, cuya existencia se hallaba seriamente amenazada a causa de la funesta desamortización eclesiástica. Hablamos de la llamada Comisión para la búsqueda y recopilación de documentos históricos procedentes de monasterios y conventos suprimidos, verificada entre 1850 y 1857 al amparo de la Real Academia de la Historia y protagonizada fundamentalmente por Pascual de Gayangos. De forma paralela, al mismo tiempo que cumplía otros encargos menores durante sus viajes -como informar a la institución sobre antigüedades y monumentos-Gayangos también colaboró activamente en la Comisión de Cortes y Fueros, destinada a recopilar todo tipo de textos y noticias sobre antiguas Cortes de los reinos hispánicos, fueros municipales y cartas-puebla que habrian de ilustrar los orígenes legales de las instituciones del Nuevo Régimen consititucional.

Antes de describir someramente la naturaleza y consecuencias de tales comisiones, es preciso aclarar los motivos por los que el papel que Gayangos desempeñó en ellas apenas ha sido reconocido hasta ahora. Uno de ellos es la dispersión de la documentación y el hecho de que dichas comisiones aún no hayan sido objeto de un estudio detallado. Al desconocimiento de estas comisiones se une la injusta — pero sólidamente arraigada - reputación de Gayangos como bibliopirata, que de manera sistemática ha llevado a la interpretación errónea y anodina de documentos cuyo contenido pone directamente al investigador tras la pista de este trascendental asunto. Sólo esa inmerecida fama explica, por ejemplo, el caso más reciente, v.g, que en el catálogo del archivo del Gabinete de Antigüedades de la R.A.H., se afirme en la descripción de cuatro documentos relacionados entre sí que tratan, junto a otros temas, "de unos cajones de pergaminos propiedad de Gayangos", cuando en realidad sólo se mencionan unos cajones con pergaminos apartados por Gayangos — se entiende, en el curso de la comisión para rescatar documentos monásticos- que iban a ser enviados a la Academia ${ }^{17}$. En otras palabras, la memoria colectiva se encarga de que toda referencia epistolar a libros y documentos históricos ajenos a Gayangos se interprete irremediablemente en función de una supuesta - más que irreprimible - codicia bibliófila, mientras las auténticas contribuciones de su vida pasan eternamente desapercibidas ${ }^{18}$. En

17 Véase Real Academia de la. Historia, Archivos de Arqueología y Patrimonio Histórico. Catálogo, indices y Reproducción Digital, dir. por A. Almagro-Gorbea (Madrid: Real Academia de la Historia, 2002): CAT/9/7974/05 (26), CAT/9/7974/05 (45), CAT/9/7974/05 (46) y CAT/9/7974/05 (49). Corresponden respectivamente a: una carta del correspondiente de la Academia en Tarragona, B. Hernández de Sanahuja, a la RAH en la que, entre otras cuestiones, trata del retraso de la Oficina de Hacienda en enviar las cajas de pergaminos apartados por Gayangos; carta en la que Sanahuja explica que el envío de esos cajones se vio obstaculizado por la oficina de Hacienda que los custodiaba con la excusa de haber empaquetado por error ciertos documentos que le eran necesarios; minuta de oficio a Gayangos dando cuenta de la carta anterior; y carta de Sahanuja en la que afirma haber estado presente en la apertura de los cajones y copia del inventario de los documentos extraídos en papel timbrado de la Oficina de Hacienda. La descripción original puede verse también en www.cervantesvirtual.com (Antigua. Historia y Arqueologia de las Civilizaciones. Catálogo de títulos, s.v. Gayangos).

18 No está de más citar aquí el concepto de "bibliófilo" tal como lo define Gayangos: "Bibliófilo es un ente por lo general raro, o que a lo menos tiene fama de serlo, erudito, amante en estremo de los libros viejos, y que no contento con los que la literatura moderna le ofrece cada día a centenares, ataviados con todo lujo y esplendor de typotipia, cifra toda su ventura ya en desenterrar un vetusto mamotreto y darlo 
otro orden de cosas, quienes se han ocupado de cuestiones afines a las comisiones desarrolladas por Gayangos han pasado por alto-o sólo han rozado circunstancialmente - el tema; en unos casos, porque se priorizaba una fase posterior de las mismas y, quizá, porque la documentación manejada no era tan elocuente al respecto como las cartas inéditas de Gayangos ${ }^{19}$; en otros, como el de la correspondencia ya publicada entre Luis López Ballesteros y Gayangos —relacionadas con el segundo y el tercero de sus viajes- no era momento de distraerse ni de restar protagonismo al tema que se trataba ${ }^{20}$. Una última y poderosa razón del lim. bo al que ha estado relegado el papel desempeñado por nuestro erudito en estas y otras comisiones es, sin duda, el nulo afán de Gayangos por figurar o arrogarse el mérito de las empresas que impulsó; en este asunto concreto, lo importante era el rescate de los documentos que servirian para construir la historia nacional.

Dicho esto, aprovechando los periodos vacacionales que le permitía su cátedra de árabe en la Universidad Central de Madrid, el cumplimiento de esas comisiones llevó a Gayangos a realizar - que sepamos por ahora- un total de ocho viajes entre 1850 y 1857, a saber, por la provincia de Burgos (septiembre de 1850), Aragón, Navarra y La Rioja (navidad de 1850/1851), Castilla y León, Asturias, Galicia, Portugal y Extremadura (jul./oct. de 1852), Murcia, Valencia, Cataluña, Baleares y Aragón (julio/octubre de 1853), provincia de Soria (diciembre de 1853), Andalucía oriental (febrero/marzo de 1855), Castilla y León, Rioja y Cantabria (agosto/octubre de 1856), y provincias de Toledo y Ciudad Real (navidad de 1856/1857). Aunque la envergadura del esfuerzo es obvia, la magnitud física e intelectual de su empeño se aprecia mejor si hablamos de un cálculo --por lo bajo- de unos diez mil kilómetros recorridos con los rudimentarios medios de locomoción de mediados del siglo XIx en España, más de setenta ciudades visitadas y un mínimo de cien depó-

a la estampa, ya en reimprimir y anotar algún libro de los muchos que el tiempo y los traficantes de papel viejo han ido poco a poco consumiendo hasta el punto de dejarle casi solo entre los de su especie; en una palabra, son los arqueólogos y anticuarios de la literatura. En España la afición a los libros viejos, tal como se entiende en otros paises, y tal cual la cultivan los individuos a que aludimos, ha sido de todos tiempos escasa, improductiva, y hasta cierto punto nula; salvo alguna que otra escepción, bien puede decirse que no ha existido». Revista Española de Ambos Mundos, 2 (1854), pp. 938-9.

19 Crespo Nogueira, C.: "Los primeros cien años del Archivo Histórico Nacional (1866-1966)", Revista de Archivos, Bibliotecas y Museos, LXXIII (1966), n. ${ }^{\circ}$, pp. 285-319; Cru? HerRanz, L.M.: "Panorama de los archivos españoles durante el siglo XIX y primer tercio del siglo XX". Historia de los Archivos y de la Archivistica en España, coord. por Juan José Generelo y Angeles Moreno López. Valladolid: Universidad de Valladolid, 1998, pp. 119-160 y "La organización de los fondos del Archivo Histórico Nacional (1866-1989)", Boletín ANABAD, XLVI (1996), n. 1, pp. 63-94; PEIRO MARTiN, L.: Los guardianes de la Historia. La historiografia académica de la Restauración. Zaragoza: Institución Fernando el Católico, 1995; Peiro Martin, I. y Pasamar Alzuria, G.: La Escuela Superior de Diplomática. Los archiveros en la Historiogratia española contemporanea. Madrid: ANABAD, 1996; TORREBLANCA LOPEZ, A.: “Erudición institucional en el siglo xix español: La sección de Archivos del Cuerpo Facultativo de Archiveros, Bibliotecarios y Arqueólogos", Erudición y discurso histórico: Las instituciones europeas (s. xvili-xix). Valencia: Francisco M. Gimeno Blay, 1993, pp. 247-264; Sotelo Martin, M. E.: La Escuela Superior de Diplomática en el Archivo General de la Administración. Alcalá de Henares: Universidad de Alcalá, 1998

20 Rivas Santiago, N.: Luis López Ballesteros, gran ministro de Fernando VII (Paginas inéditas de la Historia contemporanea de España). Madrid: Editorial Mediterráneo, 1945; GonzALEz LoPEz, E.: Luis López Ballesteros (1782-1853). Ministro de Hacienda de Fernando VII. [La Coruña]: Fundación Pedro Barrié de la Maza, 1986. 
sitos inspeccionados (administraciones de Hacienda, oficinas de bienes devueltos al clero, institutos de enseñanza, bibliotecas provinciales y otros), en los que superar la pertinaz resistencia de funcionarios estatales, provinciales y municipales -más las de algunos particulares-constituyó un esfuerzo equiparable, por un lado, al de sobrevivir al lamentable desorden y estado de conservación de los materiales; y equiparable, por otro, a la propia tarea de revisar, separar, inventariar, a veces copiar y, en más de un caso, enlegajar y empaquetar personalmente los miles de documentos que actualmente forman el núcleo de los fondos de nuestro Archivo Histórico Nacional ${ }^{21}$.

No por evidente resulta menos necesario decir que, prácticamente, la única colaboración con la que contó Gayangos, sin ser despreciable, fue de orden burocrático por parte de la Real Academia de la Historia. Igualmente, a pesar de las acusaciones de un personaje — cuando menos- siniestro como Bartolomé José Gallardo y de la fama que con tanto éxito terminó de consolidar D. Antonio Rodríguez-Moñino, también es innecesario decir que si, obviamente, Gayangos aprovechó esos viajes para ampliar su colección privada, no fue ni mucho menos con los materiales de estas comisiones académicas. En este sentido resulta significativo que, con excepción de un documento árabe de Poblet, Gayangos no publicara ningún trabajo relacionado con el material rescatado en estos viajes ${ }^{22}$ y que donara oportunamente aquellos de su colección que, adquiridos a terceros muchos años antes, podian dar lugar a ese tipo de especulaciones ${ }^{23}$.

De cualquier forma, si la deuda de los medievalistas españoles con Gayangos es aún hoy inmensa por haber hecho materialmente posible gran parte de la investigación realizada hasta nuestros días, no es menor la deuda contraída por la archivística española. No nos referimos al volumen actual del patrimonio documental conservado gracias a él, sino al propio sistema archivístico español. En primer lugar, su tercer viaje como comisionado -en el verano de 1852 - tuvo como consecuencia más inmediata la creación de la Escuela Superior de Diplomática en 1856; quizá no a instancias suyas, porque la idea existía ya y había

21 En general, lo más numeroso y destacado de sus secciones de Clero (secular y regular), Sigilografia y Códices y Cartularios. CRespo Noguelra, C.: Archivo Historico Nacional. Guia, Madrid, 1989, pp. $5,19-22,43-44$ y $57-59$

22 Al margen de que como medievalista ya es encomiable que reconociera, seleccionara y salvara de la destrucción dicho material, en el caso de la documentación obtenida para la Comisión de Cortes y Fueros - cuya naturaleza entra en la linea de otras publicaciones de Gayangos- la edición quedó a cargo de su contrapartida en la Academia, Tomás Muñoz y Romero, bibliotecario de la institución y futuro primer director del Archivo Histórico Nacional, que se encargó de recibir y organizar los fondos documentales rescatados. El resultado de su labor anónima fue la obra Colección de fueros municipales y cartaspueblas por la Real Academia de la Historia. Catálogo (1852) y Colección de Cortes de los antiguos Reinos de España por la Real Academia de la Historia. Catálogo (1855). Véase Garcia de VaLDEAvELLANO, L.: "Vida y obra de don Tomás Muñoz y Romero (1814-1867)", Boletín de la Real Academia de la Historia, CLXIII, 1 (1968), pp. 89-142, p. 94.

23 Sobre las apropiaciones indebidas que le atribuyó $A$. Rodriguez Moñino - de las que sólo una tenia cierto fundamento y ninguna relación con los materiales de estas comisiones- véase CARPIÓN GuTIEZ, M.: "D. Pascual de Gayangos y los libros", Documentación de las Ciencias de la Información, 8 (1985), p. 71-90 
fracasado varias veces, pero sí gracias al impulso final promovido por Gayangos. Su visita a los archivos de nuestro secularmente infravalorado país vecino, Portugal, reafirmó su convencimiento de que las ventajas que podía obtener una nación y la investigación histórica con la mejora de sus archivos, sólo seria posible con la existencia de un verdadero cuerpo de archiveros profesionales para gestionarlos. Su decisiva participación en la puesta en marcha de una Escuela Diplomática equiparable a la École des Chartes parisina queda probada, fundamentalmente, por la mención novedosa y explícita del modelo portugués en los sucesivos escritos elevados al Gobierno poco después de su viaje y, sobre todo, por el hecho de que la propuesta original es de puño y letra de Gayangos. Por motivos de extensión, no es posible explicar aquí las circunstancias que le impidieron firmarlo junto a los académicos Antonio Cavanilles y Pedro Sabau, razón por la que sólo ellos figuran como promotores de la feliz idea. Con respecto a la deuda de la archivística española moderna hacia Gayangos, sólo añadiremos su participación en la creación del Cuerpo Facultativo de Archiveros, Bibliotecarios y Anticuarios en 1858 y el reglamento para los ejercicios de oposición a las plazas de ingreso que elaboró siendo Director General de Instrucción Pública en 1881.

Dejando a un lado el interés de Gayangos por la numismática, la epigrafía o la arqueología como disciplinas complementarias de su faceta medievalista ${ }^{24}$, el grueso de su contribución historiográfica en relación con ese periodo se centra en la España musulmana. La impresión de que su producción científica como arabista parece escasa en comparación con los trabajos que dedicó a otros periodos de la historia de España y a la literatura medieval es sólo eso, una impresión. Conocido por su History of Mohammedan Dynasties in Spain (1840-1843) -primer estudio científico de carácter divulgativo sobre la España musulmana- también fue autor de un extenso (y aún recomendable) estudio sobre el lenguaje y la literatura de los moriscos en el British and Foreign Review (1839); de un número casi infinito de entradas sobre personajes islámicos en The Biographical Dictionary of the Society for the Diffusion of Useful Knowledge (1842-1844); de las entradas Moorish architecture, Moors, Ramadhan y Rasis -entre otras - para The Penny Encyclopaedia (publicadas entre 1839 y 1842); de la traducción de las inscripciones árabes de la Alhambra y un estudio sobre el reino de Granada en la obra de Jules Goury y Owen Jones, Plans, Elevation, Sections and Details of the Alhambra (Londres, 1842-1845), aludida en la carta que incluímos a continuación; de la edición y estudio de la Crónica denominada del Moro Rasis (1850); de la edición del diario del morisco Alonso del Castillo (1852); de la edición de unas Leyes de Moros del siglo XIV y de la Suma de los principales mandamientos y devedamientos de la Ley y Çunna del alfaqui mayor de la aljama de Segovia (1853); de un pequeño manual con los Principios elementales de la escritura arábiga y modelo de escritura

24 Sirva recordar, por ejemplo, su valioso numario (especialmente rico en monedas arábico-hispanas), las frecuentes referencias a sus informes sobre innumerables inscripciones árabes copiadas para la Academia, o su interés en las excavaciones de Medina Azahara. 
para sus alumnos (1861); y de la edición del Ta'rij iftitah al-Andalus de Ibn al-Quttiyya (cuya publicación, lista para la imprenta desde 1868, no vería la luz hasta 1926 de la mano de J. Ribera). Todo eso, sin contar otros trabajos menores. En otro orden de cosas, aunque el papel de Gayangos como patriarca de la actual cantera de arabistas españoles es habitualmente reconocido, lo cierto es que en los últimos años se ha tendido más a estudiar y resaltar el de algunos de sus discípulos o continuadores ${ }^{25}$, asi como a justificar el nacimiento del orientalismo moderno en España en virtud de razones politicas y económicas ${ }^{26}$. En el contexto de la necesaria evolución historiográfica del arabismo español desde el siglo xix hasta nuestros dias y de las circunstancias que acompañaron a cada generación con sus respectivos logros cabe destacar, sin embargo, que la creación de la cátedra de árabe de la Universidad Central de Madrid en 1843 se debió a la insistente tenacidad de Gayangos, bien documentada por los escritos dirigidos al Gobierno actualmente conservados en el Archivo General de la Administración de Alcalá de Henares ${ }^{27}$. Puede añadirse que, a juzgar por su epistolario, la fluída relación de Gayangos con los orientalistas más destacados del momento en toda Europa no tiene precedentes, ni - posiblemente- parangón con la de sus continuadores. Tampoco parece que su constancia en la adquisición de manuscritos árabes haya sido secundada hasta hoy a título privado ni institucional. En cuanto a sus materiales de trabajo, sólo diremos que la cantidad, variedad y extensión de extractos recopilados por él dan fe de su genuino interés por el contenido - no el continente- de los manuscritos que le sirvieron de fuente para iluminar el entonces desconocido periodo de la España musulmana. Sirva de ejemplo el fragmento sobre Ibn Hafșūn que Gayangos transcribió para Serafín Estébanez Calderón en la carta aquí editada ${ }^{28}$.

\footnotetext{
25 López Garcia, B.: "Cartas inéditas de Francisco Codera a Pascual de Gayangos (Reivindicación e una figura del arabismo)", M.E.A.H. XXIV (1975) 29-68; "Julián Ribera y su 'taller' de arabistas: una propuesta de renovación», M.E.A.H., XXXIII (1984-85), pp. 111-128; «Orígenes del arabismo español. La figura de Francisco Fernández y González y su correspondencia con Pascual de Gayangos", Cuadernos de la Biblioteca española de Tetuán. 19-20 (1979) 277-306.

26. Lopez Garcia, B : Contribución a la Historia del Arabismo español (1840-1917) [Resumen de tesis doctoral], Granada, Universidad de Granada, 1974 ; "Orientalismo y traducción en los origenes del arabismo moderno en España", Orientalismo, exotismo y traducción. Cuenca: Ediciones de la Universidad de Castilla-La Mancha, 2000, pp. 153-171. Sobre la historia del arabismo en España desde otros presupuestos, vease MONROE, J. T.: Islam and the Arabs in Spanish Scholarship. Leiden: E. J. Brill, 1970; Manzanares DE CIRRE, M: Arabistas españoles del siglo xix. Madrid: Instituto Hispano-Arabe de Cultura, 1971; VALLVE, J.: "El arabismo en la Universidad Complutense en el siglo XX", Catedráticos en la Academia, Académicos en la Universidad. Madrid: Fundación Central Hispano, Consejo Social U.C.M, 1993. pp. 99-106; RIVIERE GOMEZ, A.: Orientalismo y nacionalismo español. Estudios árabes y hebreos en la Universidad de Madrid (1843-1868). Madrid: Universidad Carlos III, Editorial Dykinson, 2000 .

${ }_{27}$ Madrid, A.G.A., Expedientes personales, Pascual de Gayangos.

${ }^{28}$ Por motivos de extensión y, sobre todo, con el fin de no distraer la atención de los especialistas - que identificarán sin dificultad los datos de su interés - se ha reproducido el texto literalmente prescindiendo de notas aclaratorias. En relación con el tema del fragmento, véase el reciente arículo y bibliografia citada de VAlLVE BermeJo, J.: "Omar Ben Hafsún, Rey de Marmuyas (Comares)", BRAH, CCI.2 (2004), pp. 213-303.
} 
15 de julio 1841. Londres.

Carta de Pascual de Gayangos a Serafín Estébanez Calderón. Madrid, RAH, 9/4444

9 Burton Str. Burton Crescent, 15 Julio 1841

Mi querido Serafín. Tu carta del 16 de Junio recibi antes de ayer 13 de Julio. Cuánto sea el placer que me ha causado no necesito ponderarte; pues al cabo de más de un año de no tener noticias tuyas, nada podía serme tan grato como el saber que no me habías olvidado y que aún te acuerdas de nuestras tareas Arabescas.

Sorprendido me dejas con lo que me dices de Salamanquilla. Ya yo sabía que había ganado mucho dirlero en unión con Heredia, o representándole en varias empresas, pero nunca pude figurarme que viviese con el lujo y aparato que me indicas. Por supuesto que a imitación de cuantos logran hacer rápida fortuna, ni siquiera te mira a la cara; y si lo hace será por condescendencia y por via de protección. Tu por tu parte, presumo le tratarás con el más soberano desprecio.

A tu descripción de tu situación actual, planes para lo venidero y tareas literarias, voy a contestar con la misma franqueza. Desde que no tengo carta tuya, mi posición social en este pays ha mejorado considerablemente. He sido nombrado individuo de número de la Real Sociedad Asiática, honor que, exceptuando al Barón Silvestre de Sacy, no creo se haya concedido a estrangero otro alguno. Me han dedicado algunas obras y entre ellas una con texto Árabe; me han ofrecido una plaza bastante iucrativa si quiero naturalizarme Inglés; y finalmente me ha llovido por todas partes más trabajo del que yo quiero o puedo desempeñar. Esta que a primera vista te parecerá una posición en extremo ventajosa y envidiable, no lo es, ni con mucho y por lo tanto estoy tratando de liar los bártulos y volverme así que pueda a España si, como me escriben algunos amigos, es cierto que se esté tratando de darme un destino o en la Biblioteca o en el Escorial. Me explicaré. No creo haya ejemplar en Europa de que un orientalista haya hecho su fortuna; hemos oído, sí, de Poetas y Novelistas realizar en corto número de años sumas considerables; pero los literatos, a cuya clase yo pertenezco, a no tener algo suyo o no les dan cátedras o plazas en las Bibliotecas corren mucho riesgo de morirse de hambre. Es verdad que no faltan Sociedades ilustradas que protejan esta clase de estudios; pero la protección que estas dan recae más bien sobre la obra que sobre el autor. Asi es que, si bien pasan de quince mil duros los que van gastados en la impresión de mi obra, la cantidad que a mi se me ha asignado por via de remuneración es muy desproporcionada a mi trabajo. Antes de emprender mi traducción se me dieron doscientas libras; pero estas debieron de destinarse exclusivamente a la compra de manuscritos y libros análogos a mi intento. Después he recibido $250 \mathrm{li-}$ bras o 25,000 reales por el tomo primero; y a principios del año entrante percibiré 
otros tantos por el segundo, de suerte que, contando lo gastado en libros, vendré a haber recibido 70,000 reales, que divididos por cuatro y medio años que hace que vine a esta tierra, dan el miserable cociente de 17,500. Es verdad que de vez en cuando me he solido ocupar en cosas más lucrativas, que escribo artículos en las Revistas que me pagan muy bien; que recibo 12,000 reales al año por suministrar artículos históricos y biográficos de España y Oriente a una Cyclopledia muy buena que se está publicando; pero nada es suficiente para vivir con alguna decencia en un pays en que sólo el ramo casa y criados me cuesta 12,000 reales y en el que pago por varias contribuciones directas 2000 !!

Por estas razones, y porque estoy harto de Inglaterra e Ingleses, que quiero hablar y escribir en castellano y que deseo ante todas [las] cosas que mis hijos sean Españoles y se eduquen como tales, estoy pensando, concluído que haya lo que tengo entre manos, el cambiar el roast-beef y plumpudding por el arrocillo y otros comistrajos de esa tierra. Esto, sin embargo, no podrá ser tan en breve como yo desearia. Es verdad que la traducción de Al-maccarí está -por decirlo asi- terminada, pues no me falta más que hacer el índice general y tablas cronológicas y ponerla en manos del impresor; pero me he comprometido a traducir al Inglés los viajes de Aben Batuta, que como tu bien sabes forman una obra bastante voluminosa, y tengo asimismo ofrecido al público una descripción histórica y artística de la Al-hamrá, con interpretación de todas sus inscripciones, en la cual estoy ya trabajando. Pues has de saber que se acaba de inventar aquí un método de trasladar al papel las inscripciones antiguas y que por este medio me veo en este momento rodeado de motes cúficos y Africanos. No me ha servido de poco para este trabajo nuestro Alonso del Castillo, si bien es bastante incorrecto y no copió ni la tercera parte de los letreros que existen en aquel alcázar. Concluídos que estén todos estos trabajos (si para aquel tiempo han tenido resultado favorable los pasos que estoy dando para obtener un destino en la Biblioteca, o en el Escorial, o una cátedra con una dotación decente), me verás en Madrid.

Pocos o ninguno son los libros castellanos que he comprado desde que te escribi a Málaga. Por una parte, el poco o ningún dinero disponible [y] por otra tu silencio, me obligaron a suspender la acquisición de los artículos que me tienes encargado. De dos manuscritos de poesía que te remiti a Madrid -el uno por conducto de un tal Dn. Luis Gutierrez, de Sevilla, quien me dijo conocerte y el otro, por el de un tal Dn. Pedro de la Puente - nada he sabido.

No te quede duda de que Málaga مالحقة y son la misma ciudad. Cuando la división de tierras de Andalucía entre los Árabes hecha por el Amir Abú l-jatár en el año 744, Málaga y su distrito cayeron en suerte a los naturales de una Provincia de Persia, llamada Rayya jزي (Casiri II-252, Conde 1-112). Como es natural todo

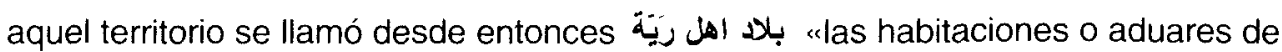
la gente de Rayya y abreviando "tierra de Rayya" del mismo modo que al distrito de Elvira se le dijo Damasco; al de Sevilla, Emessa; al de Algeciras, Al-Ordán (es decir, Jordán); al de Murcia, Misr o Egypto; al de Jaén, Kennesrín; al de Cabra, 
Waset y así a otros muchos. Averiguado el punto de que el territorio contiguo a Málaga se llamó بلاد رية no me será difícil probarte que Málaga se llamó también Rayya. La razón es muy sencilla. La palabra مدينة que ahora significa "ciudad, villa", significaba en lo antiguo capital, o sitio en donde se reunian los xefes de las tribus a donde acudían estas a proveerse de lo que necesitaban, o llevar el sobrante de sus productos; entre los Nómadas de Arabia y África, una ciudad o pueblo bastaba para cada distrito. Asi pues, cuando decimos "Medina Rayya", no ha de entenderse la ciudad llamada Rayya, sino la capital del distrito o territorio llamado Rayya. Ahora bien, el historiador Aben Al-jatib, a quien cita Casiri (Tomo II, p. 103) habla de una ciudad llamada Rayya en tierra de Archidona. Lo mismo dice Edrisi ( $p$. 28), quien también habla de un clima llamado Rayya que comprendía a Málaga, Archidona, Marbella, بيشتر Bishter y بثكسار Beshkesár. De aquí deduzco que hubo un pueblo llamado Rayya en tierra de Archidona (Arrayate?) y que a Málaga se la llamó también en los primeros siglos después de la conquista Medina Rayya, es decir, la capital de la Amelía o Tenencia llamada Rayya.

La explicación que me das de بيشتر y يُبَتَر no me satisface; que hubo un castillo famoso - y por su fortaleza casi inaccesible - llamado Bishter en la Serranía de Ronda o en alguna otra de las cordilleras que circundan Málaga, no admite réplica. En él se hizo fuerte el célebre Aben Hafsón, quien ácia el año 854 suscitó una rebelión llamada por los autores Árabes ثورة المولدين , es decir, la rebelión de los Muladíes (mulatos) que tal significa aquella palabra (hijos de Árabe y cristiano) y desafió por luengos años todo el poder de los califas de Córdova. En un tomo suelto de Aben Hayyan-tesoro inapreciable que se conserva en la Biblioteca Bodleyana de Oxford-se refieren muy por menudo las guerras de aquel osado caudillo que llegó a acorralar en Córdova a los ejércitos de Mohammed y Abdallah y se hizo señor absoluto de gran parte España. De él te copiaré dos o tres trozos para que trates de averiguar dónde estuvo puesto el Castillo de Bishter y si se conserva o no su nombre en algún despoblado.

Habiase Aben Hafsón apoderado de un fuerte castillo, llamado Hisn-Belay, en tierra de Cabra, desde el cual corría la Campiña de Córdova قنبانية قرطبة , haciendo prisioneros a sus habitantes y cometiendo toda especie de excesos y tropelías. Este castillo parece ser fue edificado años atrás por un cristiano, شربيل بن الحجاج القاموس llamado el Conde Servil, hijo de Al-hejaj, el cual se fugara de Córdova en donde vivía y como se refugiase a aquel punto, lo fortificó y pertrechó manteniéndose en él hasta que fue preso en el año 274 y traído a Córdova, en donde fue clavado en un palo. Salió pues el rey Abdallah a sitiar a Abén Hafsón en Hisn Belay بلاى Llegó a vista de aquel castillo y sentó sus reales a orillas del rí الفوشكة Al-fosheka (Al-foseca). El rebelde, confiado en el valor y número de sus bandidos, presentó al Rey la batalla, formando sus hazes al frente del castillo. El que mandaba las tropas del Califa, un tal Abdelmalek ben Umeyya, tomó una fuerte posición a la falda de un monte entre Hisn Belay y اصطرند Astarnad (otro pueblo o castillo que alli había vecino). Es derrotado 
Abén Hafsón y se retira a su castillo. Aquella misma noche se escapa montado en un asno بردون que le proporcionó un cristiano, amigo suyo - llega huyendo a Archidona cuyos habitantes le cierran las puertas. Recógese a Bishter. El Rey prosigue su marcha a Ezija, que se le rinde, y de alli a Bishter. En el año 284 de la Egira salió el Rey Abdalla de Cordova; su itinerario fue como sigue:

\begin{tabular}{|c|c|}
\hline منت شنت & Mont Shant \\
\hline جزيرة طريفة & Tarifa \\
\hline جزيرة الخضرآ & Algeciras \\
\hline مرسس الشُجرة & Puerto del árbol o de Ashajra \\
\hline حندق الجنة & Valle $u$ hondonada del jardín \\
\hline طريت خسين & camino áspero o bravo o de Jashin \\
\hline 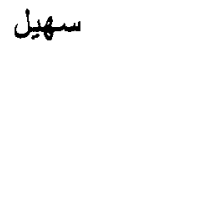 & $\begin{array}{l}\text { Sohayl, de este pueblo asi llamado porque según los astróno- } \\
\text { mos era el único punto de España desde el cual por su grande } \\
\text { elevación era visible la constelación llamada Sohayl (Canopo); } \\
\text { ya te hablé en una de mis anteriores. Estaba situada en lo más } \\
\text { alto de la Serranía de Ronda. }\end{array}$ \\
\hline
\end{tabular}

دكوان Dekuwán

el Río

Desde allí volvió el ejército a قصر بنيرة Kasr-Bineyra (o Piñeyra), a al río o valle de los Beni Abderrahmán al frente de Bishter. Por esta vez no pudo el Rey tomar el castillo de Bishter y se volvió a Cordova, rodeando por la costa: pasó por شلوبانية Shalubania (Salobreña); هنت فاية Mont Fayo; Aricún; مريقون Andarax; مرشانة Marchena; منت روي Mont Rawi; كساتئة Kasena; مدينة سامس بو الدي اش la ciudad que toma su nombre del Rio Acci (Guadix);

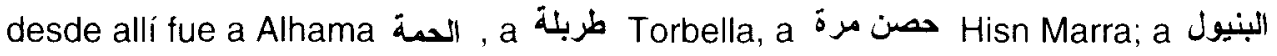
Al-beniul (Albuñol); a منتيشة Nontixa; a اوبقة Nabaca o Obaca.

En el año 295 volvió el Rey Abdalla a dirigirse hacia Bishter pero no lo pudo tomar. De allí pasó a Archidona, desde allí a الفننين Al-faneneyn, después al castillo de los Beni Kháled; después a Castellah, capital o corte de Elvira (الى قئطيلة خاصرة البيرة (Mira a Marmol Rebel. de los Mor. fo Gazela).

De todas estas citas resulta que el castillo de Bishter estaba entre Archidona y Málaga. Ahora bien, traduciendo yo días pasados a Al-homaydi, hallé que los Reyes de Málaga tenian entre los Montes alli cercanos una fortaleza casi inacce-

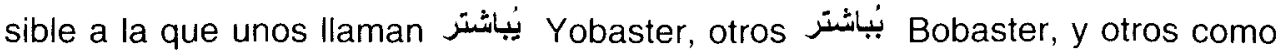
Conde y Casiri Yebaster. No quiero decir por eso que los dos sean un mismo sitio, 
pues aún cuando tengo sobrada experiencia acerca de las alteraciones que de un siglo a otro se han introducido en los nombres de los pueblos árabes, cambiandose estos a menudo según el capricho u antojo de los pobladores, o desapareciendo enteramente del mapa por efecto de alguna incursión, no me atreveria a asegurar puedan ser identificados. Al contrario, me inclino a creer son distintos puntos. Otro castillo famoso llamado Airós o Aires ايرش había también en cercanías de Málaga. Mucho me alegro que no hayas del todo abandonado la idea de ilustrar la Geografía de la provincia por medio de los historiadores y geógrafos Árabes. La empresa es ardua, pero si la desempeñas bien te dará nombre entre los literatos de Europa; pues hoy dia se están haciendo los mayores esfuerzos aquí y en Francia y Alemania por ilustrar la historia y geografía de Europa durante la Edad Media y la de España no puede menos de interesar por reunir en sí los vestigios de tantas lenguas y naciones. Ya sabrás que se ha hallado en la Biblioteca de París la obra completa del geógrafo Edrisí (mal llamado Nubiense pues no era natural de Nubia, sino de Cordova) de la cual lo publicado por Conde, quien no hizo otra cosa que traducir la versión Latina de 1602 impresa en París, reproduciendo sus enormes disparates, no es sino un ligero extracto. En la Biblioteca Bodleyana hay dos exemplares que yo he consultado y de donde he sacado noticias importantísimas. También he leído las de Al-becri, Aben Haucal, Al-beladhorí, Al-istakhrí, y otros que precedieron de mas de dos siglos al viajero Africano y le aventajan mucho en noticias y detalles. Como de todos estos autores tengo hecho copiosos extractos, pienso formar con el tiempo una especie de Diccionario Geográfico Árabe-Hispano, pero para esto se necesita conocer la España presente y yo he viajado muy poco por ella.

Volviendo al asunto de los libros, hoy recibo una carta fha. Sevilla 17 de Junio, en que Dn. Pedro de la Puente y Aperechea, me dice que durante su permanencia en Madrid te ha buscado con diligencia para darte el libro que yo le dí para ti, pero que no le ha sido posible averiguar tu paradero. Me dice asi mismo que su hermano Dn. Fermín, que es Poeta, está enamorado de él y ofrece comprármelo. Le voy a escribir que no puede ser y que es tuyo ya y que te lo remita. Es una colección de varias poesías hecha a principios del siglo xVII, entre las cuales se halla gran parte de un Poema que si no me llamo a engaño, es el Demofonte, que estaba en la Librería de Gómez. Del otro manuscrito que contenía poemas por la mayor parte inéditas del mismo tiempo y que te mandé por el Gutierrez nada he vuelto a saber. ¿Lo tienes acaso en tu poder? Dias pasados se hizo aqui venta de los libros de Gómez, pues Ternaux que compró residuo de su biblioteca después de haber tomado todo lo relativo a América ha vendido lo restante. El librero Thorpe tiene aun los Romances y otros pero sin rebajar ni un cuarto de su precio primitivo. Usoz anda comprando bastante. Por la primera ocasión que se presente, pues en Londres eso no es tan fácil como tu imaginas, te remitiré algunas cosillas Qué cabeza tienes! no me dices dónde vives y tengo que incluir ésta a mi Madre para que te la envie. Memorias a Matilde, mias y de Fany; un beso a los niños y recibe afecto de tu amigo Pascual. 